\title{
Assessing the Look East Policy: Moving Beyond Work Culture and Ethic
}

\author{
Kartini Aboo Talib @ Khalid $^{1}$, Nidzam Sulaiman ${ }^{1}$, Suzanna Mohammed Isa ${ }^{1} \&$ Suhana Saad ${ }^{1}$ \\ ${ }^{1}$ Institute of Ethnic Studies, Faculty of Law, Faculty of Social Sciences and Humanities, Universiti Kebangsaan \\ Malaysia, Malaysia \\ Correspondence: Kartini Aboo Talib @ Khalid, Institute of Ethnic Studies, Universiti Kebangsaan Malaysia, \\ Malaysia. E-mail: kartinikhalid@gmail.com
}

Received: July 3, 2013 Accepted: September 12, 2013 Online Published: November 29, 2013

doi:10.5539/ass.v9n17p111 URL: http://dx.doi.org/10.5539/ass.v9n17p111

Authors would like to thank the Sumitomo Foundation for the financial support a code grant RE2012-003 Reg. No. 118426, Mr. S Sakakibara and Mr. K Ishizuka. We also acknowledge and thank Dr. Karen Vautour in Salem Massachusetts for editing and proof reading this manuscript.

\begin{abstract}
The Look East Policy (LEP) was introduced in 1981 after former Prime Minister Mahathir's East and West competing perspectives contributed to a nationalist enthusiasm to turn Malaysia into a new industrialized country using Japan and Korea as models. This paper reassesses LEP within the framework of policy evaluation and addresses its long-term impact, with a few twists. For the purpose of this article, only Japan will be discussed as a model for LEP. This article argues that LEP has contributed to Malaysia's progress in becoming an industrialized country. This research applies assessment indicators such as input, output, processes, performance, and cost considerations to evaluate the achievements made by LEP in terms of work culture, ethics, investments, and human capital development. Intensive interviews were conducted with 30 respondents from various organizations with similar profiles, each contributing experience such as studying, living, working, co-operating and collaborating with Japanese counterparts. Themes were developed based on sequential questions occurring in the narrative interviews' transcriptions. This study shares respondents' voices and it reports them as they are. The findings show that LEP produced both advantages and disadvantages, but the former seem to blend in better in organizations, individuals' lives, and an incremental effort to establish a strong industrialized state.
\end{abstract}

Keyword: look east policy, evaluation, work culture, implications

\section{Introduction}

Models for development have always been referred to by most pre-industrial nations as guidance because they illustrate many stages of trial and error. Such ready-made models could help leaders to make adjustments to an established method rather than designing a new one from scratch. In fact, learning from others' mistakes could be considered practical and wise. The same practical idea also inspired Mahathir, the fourth Prime Minister of Malaysia (1980-1998), to bring his country into its own industrial age through the Look East Policy. Buy British Last was an anti-western sentiment within Mahathir's administration that reflected his patriotic intention to lead Malaysia away from colonial influences and dogma. The leading inspiration for Mahathir was the story of Akio Morita, the founder of Sony, who went through tremendous bitterness before Sony was established as a strong brand product and a global business empire. This story in tandem with his Vision 2020 agenda demanded that all Malaysians should look east for a better future. In a similar fashion, another poor country, Korea, was able to develop rapidly and against the odds in the 1960's, despite being politically separated by liberal and communist forces. Mahathir visited Korea in the 1960s and was moved to later watch that sleeping tiger wake and roar with rapid advanced development. (Note 1)

Based on his experiences, former Prime Minister Mahathir turned most governing structures into ones following Japanese and Korean models of organisation, particularly in the arenas of work culture and ethics. Thus, this article is meant to reassess the Look East Policy (LEP) using the Japanese model of organization, cultural influence, multi-national corporations (MNC), education, technical or training programs, and work ethics. This 
reassessment may be the first phase of evaluating the LEP after thirty years of practice. Choosing to reassess the Japanese LEP model is determined by the availability of a research grant and the fact that Japan's influence and involvement in Malaysia has been more substantial than Korea's in terms of direct investments, financial assistance and loans, work culture and ethics, and educational programs.

Furthermore, reassessing the LEP through a policy evaluation framework allows for consideration of indicators such as input, output, processes, policy performance, and cost. Top down policy implementation explains the central roles played by the officials in a few governmental agencies in making the LEP a realized national agenda despite its absence of a policy blue print. Additionally, the policy evaluation framework highlights evidence that recognizes LEP as a successful policy as it contributes to changes in organizational work systems, both in public and private sectors, as well as individuals' work ethics.

\section{Methodology: Intensive Interviews and Themes}

This research applied a qualitative approach to gather the substantive impacts of LEP rather than assessing the size or scale of people's perceptions through surveys. Participation, observation and intensive interviews were employed. Observations were made on 12 (7 public and 5 private) organisations in Penang, Federal Territory Putrajaya, and Selangor. Of particular interest were their organisational charts, mission and operation statements, and actual practices. Thirty people in total voluntarily participated in intensive interviews. The sampling method for selecting the private and public agencies was random while selecting respondents for intensive interviews was a snowball sample, with the sample size gradually increasing due to personal recommendations. A common criteria that all respondents had was their direct experiences with Japanese counterparts: either they formerly were students at the Japanese varsities, formerly or presently living in Japan or working with a Japanese MNC, undergoing on-the-job training or technical skills enhancement in Japan, teachers enrolling in Japanese language learning programs, or government officials who were directly involved in formulating and implementing the LEP.

For this qualitative method, intensive interviews provided an excellent conversational analysis to capture how people construct their realities and highlight their points of view through description and explanation of their own experiences (Berger \& Luckmann, 1967; Zimmermann \& Wieder, 1970; Coulon, 1995; Taylor \& Bogdan, 1998). The same list of open-ended descriptive questions was given to all respondents that enabled them to talk about favourable topics without structuring exactly what the responses should be. Free-flowing dialogue and an active probing technique were applied during the interviews. Furthermore, repeated face-to-face encounters were conducted to understand respondents' perspectives on their personal experiences with Japanese organisations and to understand the work ethics and cultures that have been accepted and incorporated into their daily lives. Interview statements were taped and transcribed.

Themes and unifying concepts were developed based on words and recurring conversational topics provided by respondents through statement comparison and analysis. Identifying themes, constructing typologies and relating different pieces of data to each other allowed this research to uncover the variability of factors associated with the Look East Policy. Informants' stories were cross-checked with one another and compared with agency documents such as employee attendance records, achievements, records of programs and training provided by the government for Malaysian students in Japan. Nevertheless, the results from this research will not be used for generalisation because this method may over- or under-represent findings.

\section{Discussions in the Past}

Several themes were present in previous studies on the Look East Policy that specifically addressed the Japanese model being applied in Malaysia: foreign assistance, Japan's profound interest in investments, the homogeneity of Japanese culture compared with Malaysia's complex plurality, and bilateral relationships between Malaysia and Japan. These themes emerged during data collection between the 1980s and 2007. Most of these observations were developed based on secondary facts and none presented a primary data source for understanding individual's standpoints and experiences on the impact of LEP. Thus this article means to go deeper in expounding the individual's experiences, perspectives, and emotions related to LEP.

Atarashi (1985) argues that Japan's interest in ASEAN (Association of Southeast Asian Nation) is genuine, ranging from trading to investments. Looking at ASEAN as new lands for investment is significant for the Japanese economy because efforts to open markets and to expand imports of manufactured goods would reduce trade friction with the United States and the European Community. Also debt risks and political instability in Southeast Asia cause Japan to focus on the need to revitalise these country's economics. Japanese technologies and management skills have reached a maturity level which now enables Japan to carry out its production activities in the developing countries that would be mutually beneficial. Thus, Atarashi (1985) further argues that 
each country in ASEAN has its own model of the Look East Policy without necessarily needing a blue print of it. Malaysia's LEP was initiated in the 1980s after Nakasone created a strong impression on Mahathir to firmly introduce LEP to help the nation develop rapidly using the Japanese model. Despite criticism of his personal denunciation of LEP, Mahathir led this nation to become a new industrialised country with a Japanese-inspired work culture.

Although Japan's Foreign Aid policy in international development is massive and substantial compared to most countries, Japan is not yet a leader (Rix, 1990). Japan is doing its best as a financial supporter in shouldering globalization responsibilities, but criteria to be the world leader must also include the possession of resources and politico-military superiority. Japan is carrying significant financial burdens in dealing with a number of developing countries as well as their needs for aid coupled with their domestic issues and risks. Such matters may dissuade investors from the West but Japan is able to accept their shortcomings and it continues to be supportive. Therefore, Japan's contribution is effective regionally, particularly in Southeast Asia (Note 2) due to its geopolitical convenience and rich resources. This strategy makes Japan the most reliable partner with Asian values and is seen as less manipulative, and perhaps more reliable in fostering and leading regional development accordingly. Concerns about international manipulation were one of the reasons that urged Mahathir to reject the financial assistance package from IMF during the Asian financial crisis in 1997-1998 and redirected its financial dependence to Japan.

Furuoka et al. (2007) and Furuoka (2003) comprehensively expounded the issues of Japanese foreign aid policy, particularly Japan's Official Development Assistance (ODA) program to Malaysia that is prominent and vital for Malaysian development. Malaysia is the fourth largest recipient country under this program. Japan is the largest trading partner to Malaysia and its financial aid has benefited Malaysians in many ways including job opportunities, venues for technology transfer, and investments of more than USD 3.314 billion between the years of 1995-2000. Furthermore, under the New Miyazawa Initiative, the Japanese government provided funds for human development programs to improve knowledge and skills through education. Under the LEP, scholarships are given to Malaysian students to pursue their studies in Japanese varsities. In the HELP II program, engineers are trained in Malaysia first and are later sent to Japan for advanced courses and training. Although the intention of this policy is a clear way for Japan as to assist in the development, security and prosperity of the international community, the ODA has been criticized by the Japanese because of its increased tax burden its citizens at home. As a matter of fact, Hook and Zhang (1998) argue that the Japanese government is reviewing its foreign aid policy and would use this instrument strategically to promote its own economic revival.

Khadijah (2004), Lee (2004) and Zielinksi (1998) criticize that LEP has been far from successful in turning Malaysians toward Japanese values of strong work ethics including punctuality, consensus, and loyalty. Malaysians are finding the Japanese model too robust and difficult to be implemented easily. Many Malaysians are lacking those qualities and are hampered by old fatalistic mindsets. In addition, the Japanese models of business practices related to trade relations, such as the sogo soshas principle and the gakubatsu bond, are difficult to achieve in a multiethnic superstitious society; in-house unions and system operation preferences are viewed as unfit for Malaysians. Furthermore Malaysians argue that a pro-Japan orientation does not help to promote the Malay or the indigenous participation in entrepreneurial activities. For instance, out of 1200 students sent to Japan, only 12 managed to be successful in entrepreneurship (News Strait Times, 1997). The above authors speculate that even without a formal policy of looking east, Japan would still have invested in Malaysia as new markets of supply and demand that would reciprocally benefit Japan and its counterparts. It is all about capitalism, money and nothing more.

Despite these unaccomplished goals of LEP, Furuoka (2007) argues that Japanese investors' high degree of pragmatism has encouraged Japan to support Asia even when Asia was at its most vulnerable financial crisis in 1997-1998. Furuoka (2007, p. 510-512) adds that Japanese rescue packages managed to empower Asia, particularly Malaysia, to rally after the crisis and to ensure that human capital development would be sustainable for the foreseeable future. For example, a loan of \$137 million enabled 1,400 Malaysians to study in Japan during the crisis of 1998-1999 and another injection of \$75 million was allocated for scholarships for Malaysians enrolled in engineering and science courses provided under the Japanese Higher Education Loan Fund II. In fact, Japanese MNCs have demonstrated a long-term commitment to Malaysian subsidiaries over decades including Sony, Hitachi, and Matsushita-Panasonic. Continuous Japanese investments in Malaysia have enhanced the nation in several ways including job opportunities, urban development, human capital development, and the bilateral balance of power between Japan and Malaysia. 


\section{The Look East Policy: A Policy Evaluation}

Policy cycles are composed of five distinct stages that foster understanding: acceptance, formulation, decision, implementation and evaluation (Howlett \& Ramesh, 1995). Each different stage involves several scholarly views that can be carefully explicated to provide a complete understanding of each stage from the definition to the mechanism and factors that contribute to influencing the outcome. Each stage is connected to another and the evaluation processes usually happens after years of implementation of a policy. Ample time should be given for a policy to develop, grow, and mature. An evaluation process may or may not be necessary only when a public problem has emerged. Most of the time an evaluation is a necessary process to demonstrate whether or not an implemented policy is producing positive outcomes.

Majone (1988) argues that assessing policies is a challenging work. To develop a method of assessment is not simply expressing judgment of pass or fail; it must be able to emphasize the learning and adaptive mechanisms that help improve the policy over time. The purpose of policy evaluation as noted by Weiss (1998) is a way of increasing rational policy making, wherein a policy that produces positive outcomes should be expanded and one that produces negative or ineffective outcomes should be dissolved or abandoned. In fact, a report or information from an evaluation process could always be used to design program activities that are more innovative and effective for the public.

Policy evaluation consists of assessing an ongoing public policy or program empirically to see whether or not that policy or program is able to attain its actual stated objectives (Nachmias, 1995; Howlet \& Ramesh, 1995). The indicators that apply to assessing a public policy or program including inputs, outputs, performance comparisons, costs, and the process or procedures in delivering the policy or program (Howlett \& Ramesh, 1995; Mayne \& Hudson, 1992; Peter, 1992; Palumbo, 1987; DeLeon, 1983). These indicators have been utilized to varying degrees by different governments around the world, limited primarily by level of sophistication and comprehensiveness of the assessing reports. Therefore, this research evaluates LEP using indicators such as inputs, outcomes, policy performance, processes and costs as they impact individuals and the nation of Malaysia as a whole.

\section{A Policy Assessment: Achievements, Processes, and Impacts}

In applying the assessment indicators, the first indicator is inputs. Within this context, input is the efforts made by state actors to realize and achieve the policy objectives. The establishment and introduction of LEP in early 1980s looked more toward a national agenda than a blue print policy. Former Malaysian Prime Minister, Mahathir Mohamed, initiated and implemented LEP and was very patriotic in his thinking about national development being achieved within the LEP model and perspectives relative to western ideas of modernization. The LEP was sanctioned as a policy by Mahathir to promote the idea that the whole nation should be obliged to move forward after this fashion. The primary objective of LEP was straight-forward emulation of Japanese work culture and ethics that could help to prepare the society for industrialization. Secondly, LEP would signal Japanese investors and industries that Malaysia's commitment was serious and could thus become a strong bilateral relationship based on the Japanese model that would advance local industries and modernization. Preparing the nation with Japanese work culture and ethics would provide better accommodation among Japanese investors towards minimizing the risk of dealing with the cross cultural complexity embedded in a plural society like Malaysia.

Furthermore, this straight-forward national agenda of LEP was actually a top-down policy implementation. The objectives of LEP were disseminated to all ministries including units and agencies, and the private sectors were encouraged to enter into business ventures with Japanese companies. The instructions from the Executive Office were bold and firm. Government and private sectors were strongly encouraged to look east when designing their own organizational systems and processes based on the Japanese models. Another bold step was to send Malaysian students to good varsities in Japan immediately after the LEP took effect in 1981. Thus budget allocations allowed for the first objective of LEP to be realized by developing social capital through academic and skills training. The incremental long-term impact has been profound in creating generations that have a firsthand experience in understanding and practicing Japanese culture and ethics. From 1982 through 2010 the LEP enthusiastically sponsored many Malaysian students in Japan. The Public Service Department (JPA), a government agency responsible for providing scholarships to study abroad, has sent out a total of 12,593 students to Japanese tertiary education institutions, and from these numbers a total of 3, 226 were undergraduate programs (Koda et al., 2011). While still ongoing, the number of Malaysian students studying in Japan has fluctuated due to individual preference, cost, and program availability. 
Post-graduation employment is another objective achieved through LEP-sponsored higher education programs. Yoshiko, et al. (2011) cite that graduates receiving grants from the Higher Education Loan Project (HELP) have been employed in manufacturing sectors immediately following graduation and that since 2006 most HELP graduates were likely to stay in Japan due to the Japanese government's favorable immigration policy. Therefore, Yoshiko, et al. (2011) note that the LEP induces a strong preference for Japanese investors and FDI to see Malaysia as their favorite business location and that the Japanese financial assistance in education, especially ODA and HELP, has played a complementary role in the development of highly skilled human resources for the engineering and electronic industries that are the largest manufacturing companies in Malaysia.

The second indicator is the process applied in delivering the LEP by government agencies to the business and non-business communities. The Malaysian central government was the pioneer that initiated LEP to be adopted and implemented in both public and private sectors. The implementation process was not complex or cumbersome because of a strong concentration of power at the centre that simply dispersed its instructions as mandatory. The Executive branch was responsible for policy enforcement and all government agencies were obligated to implement it in a straight-forward, unchallenged manner. Public and private sector businesses were expected to incorporate LEP's two-fold objectives into their operating plans, sometimes without a proper blue print for implementation. Moreover Mahathir, as an authoritarian leader, chose LEP as his top priority and allocated a budget with the objective of mobilizing Malaysian resources towards an industrialized society by 2020 (Khoo, 1995; Milne \& Mauzy, 1999; Wain, 2009).

The third indicator is the outputs or outcomes resulting from LEP that reflect its objectives. On one hand Khadijah (2004), Lee (2004), and Zielinski (1998) lament the Japanese model as unfit for Malaysians because they are still stuck in a fatalistic mindset. Khadijah (2004) was referring to the youth groups without proper qualitative or quantitative methods to account for such shallow accusation, exposing a flaw in that research design. Youth around the world share similar behavioral issues in most communities; with rushing adrenaline and hedonistic tendencies, they are quite unstable and used as an example of representing the entire Malaysian population. In fact, employed Malaysians tend to be educated, and bound to agency rules and work systems. Additionally, this research also rebutted Lee (2004) and Zielinski (1998) remarks of the unfit Japanese model because most public agencies in Malaysia are likely to utilize the 5S (Note 3), kaizen, kanban system, and JIT (Just-In-Time) in their daily operation. Two of several key performance indices used to evaluate workers are discipline and accountability. While the private sector expressed its independent model of operation, most companies are applying the $5 \mathrm{~S}$ when it comes to managing files and documents. Moreover, the JIT and kanban system are applied in a way that would increase their productivity and quality. Other aspects such as loyalty and honesty are also included in their main emphasis and most private and public sectors agreed that these values reflect the LEP principles. Japanese elements are prominent and work well with organizational objectives and operations.

Furthermore, most respondents share a similar opinion that the 5S, kanban, and JIT systems have helped them manage their daily routine better than having an individual way of operating agency tasks, or no guideline at all. For the $5 S$ method, documents and files are updated every 6 to 12 months, making files systematic and easy to review and access at any time. In fact, waste is reduced tremendously and at a few operational stages redundancy and waste are eliminated completely. Moreover, Japanese work ethics emphasize respect, courtesy, discipline and efficient services to clients. Governmental or public sectors applying the $5 S$ method include the Ministry of Higher Education, Ministry of Education, Ministry of Health, Ministry of Human Resources, Department of Public Registration, Department of Public Services, Ministry of Women, Welfare and Rural Development, Department of National Treasury, and hospitals. Similarly private sectors including heavy industries such as Perodua, Proton and many local entrepreneurs also subscribe to this method.

The kanban system allows for each process in multiple stages to be checked and if there is a defect in a process, a person responsible for that particular task or station will be held accountable. A worker must fix the problem quickly in order to avoid the process from continuing to make a mistake at a different level of operation. In addition to the JIT system, it allows the manufacturing companies to streamline their entire operation and to maximize the use of resources with zero waste. With storage for possible future orders, it also encourages the industry to operate efficiently according to recorded orders for products. The supply of products is provided by confirmed demands from clients. Such practice works well in a few local manufacturing companies such as Perodua and Proton-DRB Hicom. The JIT system is a solid operating system that has been used by other western companies including IBM and Hewlett-Packard, albeit by different names such as direct flow manufacturing and output with zero stock (Aziz et al., 1988). 
Additionally, from individuals' experiences and standpoints, most respondents reveal that they keep the discipline, punctuality and accountability in their personal lives and ensure that these values are cultivated within their family and children. A few respondents express that the Japanese work ethics are something to strive for and to most Malay respondents these values conform with the high standards of the Islamic way of life. In fact when it comes to respect, hygiene, and honesty the Japanese managers and officers are the role models. Some respondents that have lived in Japan for many years express that the Japanese values seem to blend well with their own attitudes and actions. Many Malays have learned to keep self- disciplined, organized, and punctual when making appointments or attending meetings. They like to be detailed in executing their daily tasks, learning about the risks, finding solutions to avoid any unprofitable risks, or trying to overcome possible disadvantages at work. Japanese people appreciate standardized procedures in all processes, and the same appreciation is applied by most respondents and agencies in maintaining rules and regulations, and in following procedures strictly to avoid defects or damage.

A few respondents shared their adherence to tidiness principles to the extent of placing their shoes facing forward in Japanese fashion to facilitate ease of movement. Others kept the Japanese protocol of buying and selling items where a total quantity of items scanned is delineated for the customer together with the total amount. Written receipts are coupled with verbal confirmation of the exact amount of money a teller receives from a customer, putting the exact amount beside the machine, counting the change and confirming to a customer the total amount and change that the teller is rendering. Such details are designed to eliminate confusion between both teller and customer that sometimes occur when the exact amount of money that is given or received is in question. Malays studying in Japan have reported some life changing experiences that have inspired the younger generation to pursue honesty and good moral behavior, particularly teachers of high school science and Japanese language curricula.

Despite admiration for the Japanese values of integrity and discipline, a few respondents expressed their dislike of the hierarchical form of society that seems to favor the wealthy, allowing them to denounce people at the bottom economically, and particularly ordinary workers. A few respondents voice their dissatisfaction in dealing with their Japanese counterparts when a series of encounters with them showed that acknowledgement is only recognized to their boss or superior. Eye contact is only for superiors and no courtesy is shown to lower ranked employees even when they are meeting at the same table. The most silent and observant is the superior rank while the subordinates do most of the talking. Often such a scenario creates an uneasy feeling among them. Adding to that discomfort, their Japanese counterparts' extremely meticulous attitudes in striving for a risk-free business may run cross grain with them and demoralize more than inspire their feelings toward Japanese work culture.

The fourth indicator is assessing policy performance, including mapping the growth and increased investment, engagement and co-operation between Malaysia and Japan. The LEP may not be the main factor for Japanese investors to land their investment here, but the policy reflects the seriousness of the Malaysian government in pursuing its bilateral relationships with Japan. The advantages of cheap and skilled workers, incentive packages, stable political and social conditions, respect and hospitality of the host country fascinate Japanese investors and keep their economic favor and faith in Malaysia. Furthermore, increasing numbers of Malaysian workers educated in Japanese schools will sustain and enhance this win-win bilateral co-operation for years to come. Thus, Japanese work ethics and culture are becoming commonplace among Malays, and the domino effect will take place in the organizations and communities without the awkwardness of many transitions.

Md. Izwan (2012) and Saraswathi (2009) note that Japanese investments are substantial and positively growing in Malaysia. For instance from 1995 to March 2000, Japan invested a total of USD 3.314 billion in Malaysia. In 2008 USD 1.6 billion was spent with 60 projects approved, and between January and September 2009, the investment increased from USD 1.6 billion to USD 1.87 billion. Additionally, from 2011 until the present there have been more than 2,422 active manufacturing projects worth of US $\$ 19.5$ billion invested by Japan in Malaysia, making Japan the largest foreign investor in this country. (Note 4) Most Japanese investments are concentrated in manufacturing electronic products, non-metallic mineral products, petroleum-based products, chemical products, transportation equipment, and metal fabricated products. Such huge progressive investments from Japan show the element of trust and capability with which Malaysia is able to profitably reward Japan.

The final and foremost indicator is assessing the cost incurred from the LEP. Although assessing a program using this indicator might seem straight-forward and easy by calculating cost effectiveness and implementation, it is not absolute. In the case of LEP, it is difficult to access information from the Public Service Department, the Prime Minister's Office, and a few other government agencies that are also involved in implementing the LEP. These accounts are not subject to public scrutiny and the application of both the Official Secret Act of 1972 
(Amended, 2006) and the Sedition Act of 1948 may be used under the name of national security to withhold information. Initially LEP was directed towards human capital development, and there is no doubt that costs incurred for such investment are huge. In the long run it is not so much about the cost because many programs including higher education, tertiary and skills training are being subsidized by Japan. Malaysia has so much more to gain than to lose in this bilateral co-operation, despite some critics dwelling on the high interest of Japanese loans that continue to suffocate a newly industrialized country like Malaysia (Hook \& Guang, 1998).

\section{Moving Beyond Work Culture and Ethics}

Culturally unfit is no longer an issue because positive behaviors such as integrity, accountability, and loyal dedication at work are culturally accepted and integrated within Malaysian pluralistic local cultures and beliefs. Although "Turning Japanese" may not be the right term to depict the positive and innovative attitudes, modeling and nurturing many Japanese behaviors are rewarding to Malaysians. In fact, Japanese organizational operating systems prove to be exceptional and are working well in most public and private sectors. Thus the LEP is now moving forward to strengthen its modus operandi by more closely collaborating and co-operating with Japan than before. One new idea from respondents including Mahathir is the need to establish Japanese higher learning institutions that are fully operated in Malaysia with actual Japanese cultural applications in all aspects of teaching, communicating, researching, and innovating, thereby projecting a solid acculturation within Malaysian society. Institutions on Malaysian soil would benefit more than just a selected few students that could be sent abroad in order to gain exposure. Instead of sending, it is time to bring them here. Education is still the best tool to cultivate and nurture the foundation. It is cost efficient to Malaysia, and the advantage will be shared by the Japanese in terms of minimizing the risks caused by natural disasters in their own country.

Another new aspect is emerging markets for the Japanese in services sectors, particularly the Japanese small and medium companies (SMEs) that are keen to introduce and market their products in Malaysia. Japanese businesses have been focused on manufacturing but are now willing to venture into the Halal hub markets in Malaysia and are looking forward to investing in the service sectors (Rupa, 2012). This new development will add to the already diverse foods and packaging markets in Malaysia. Such business opportunities will further open up for possible food manufacturing industries in Malaysia. Massive production and commercialization to meet the supply and demand from the global market would motivate Japan to position Malaysia as its favorite destination for much investing and manufacturing, not limited to electronic goods and engineering expertise.

Moreover, encouraging the Japanese to build their research and development (R\&D) centers in Malaysia would hasten technology transfer. Sharing innovations and inventions will benefit both industry and society through co-operation that enhances employment, living standards, cost efficiency, and new market profitability. Perhaps the idea of having a global society that is mobile and moving in terms of providing support and sharing innovations to improve the well-being of the people is no longer an imagined community but a reality in the making. Japan should have the freedom to independently bring its resources in terms of innovation, research and development, and strong positive work cultures to the global market without waiting for American approval. One of many opinions expressed by some respondents is the eagerness to see Japan, and especially Sony, re-emerge with its excellent track record of invention and innovation, being able to compete with Apple and Samsung. In the words of Mahathir, "Japan is struggling with its slow economy due to her close encounters with the US and the challenging inventions of Apple. It is like being against the guru, and now Sony is far behind not just Apple but Samsung." Perhaps the subservient and loyal cultural feeling that Japan has towards America, its father of modernization, causes setbacks for Japan. (Note 5)

\section{Conclusion}

The LEP is pivotal to Malaysia's entire model of modernization and industrialization. Its vast contributions to changing the traditional attitudes into a robust, disciplined and integrities working culture will continuously affect Malaysian communities because the emphasis on positive behavior is conforming with the belief and values embedded in its communal societies. Thus Japanese work culture and ethics are exceptionally acceptable in this society. In fact, thirty years of policy implementation shows a strong foundation of trust and confidence in the Japanese organizational operating systems and these systems are well applied in most public and private agencies in Malaysia. Although expectations of how far Japanese culture and values will influence individual daily lives is a matter of personal preference, for thousands workers at several Japanese MNCs, alumni of Japanese schools, government officials, entrepreneurs, and local private sector workers, the Japanese work culture and ethics are part of their daily practices at work as well as in their personal lives. Thus, looking east has set Malaysia on a whole new level of development that is an eye opener not only to third world countries but also to the West. 


\section{References}

Atarashi, K. (1985). Japan's Economic Cooperation Policy towards the ASEAN countries. International Affairs (Royal Institute of International Affairs), 61(1), 109-127. http://dx.doi.org/10.2307/2619782

Berger, P., \& Luckmann, T. (1967). The Social Construction of Reality. Garden City, NY: Doubleday.

Boyd, A., Geerling, T., Gregory, W. J., Kagan, C., Midgley, G., Murray, P., \& Walsh, M. P. (2007). Systemic Evaluation: A Participative, Multi-Method Approach. The Journal of the Operational Research Society, 58(10), 1306-1320. http://dx.doi.org/10.1057/palgrave.jors.2602281

Coulon, A. (1995). Ethnomethodology. Newbury Park, California: Sage Publication.

DeLeon, P. (1983). Policy Evaluation and Program Termination. Policy Studies Review, 2(4), 631-647. http://dx.doi.org/10.1111/j.1541-1338.1983.tb00793.x

Furuoka, F. (2003). Economic Relations between Malaysia and Japan: Investment, Trade, Economic Assistance. Borneo Review, 13(2), 130-145.

Furuoka, F. (2007). Malaysia-Japan Relations Under the Mahathir Administration: Case Studies of Look East Policy and Japanese investment in Malaysia. Asian Survey, 47(3), 505-519. http://dx.doi.org/10.1525/as.2007.47.3.505

Furuoka, F., Lo, M. C., \& Kato, I. (2007). Japan's Foreign Aid Policy towards Malaysia: Studies of the New Miyazawa Initiative and the Kelau Dam construction. Economic Journal of Contemporary Japanese Studies. Retrieved April 18, 2013, from http://www.japanesestudies.org.uk./articles/2007/FuruokaLoKato.html

Giandomenico, M. (1988). Policy Analysis and Public Deliberation. In R. B. Reich (Ed.), The Power of Public Ideas. Cambridge, Massachusetts: Ballinger.

Hamid, A. A., Hassan, M. E., \& dan Arawati, A. (1988). Amalan Konsep Pengeluaran Just-In-Time: Kajian Kes Sebuah Syarikat Perkilangan di Malaysia dan Pembekal-Pembekalnya. Journal Pengurusan, 6\&7, 3-19.

Hook, W., \& Zhang, G. (1998). Japan's Aid Policy since the Cold War: Rhetoric and Reality. Asian Survey, 38(11), 1051-1066. http://dx.doi.org/10.2307/2645685

Howlet, \& Ramesh. (1995). Studying Public Policy: Policy Cycles and Policy Subsystems. New York: Oxford University Press.

Izwan, M. (2012, October 10). Dasar Pandang ke Timur Perlu disambung dan dibangunkan, kata PM. Retrieved May 2, 2012, from http://www.themalaysianinsider.com/print/bahasa/dsar-pandg-ke-timur

John, M., \& Hudson, J. (1992). Program Evaluation: An Overview. In J. Hudson, J. Mayne \& R. Tomlinson (Eds.), Action Oriented Evaluation in Organization. Toronto: Wall and Emerson.

Khalid, K. M. (2004). Malaysian-Japan Relations under Mahathir: Turning Japanese? In B. Welsh (Ed.), Reflections the Mahathir Years (pp. 325-332). Washington: The Paul H. Nitze School of Advanced International Studies (SAIS).

Koda, Y., Yuki, T., \& Hong, Y. (2011). Cross-Border Higher Education for Higher Education for Labor Market Needs: Mobility of Public Funded Malaysian Students to Japan over years. No. 29, JICA Research Institute.

Milne, R. S., \& Diane, K. M. (1999). Malaysian Politics under Mahathir. London: Routledge.

Nachmias, D. (1995). The Role for Evaluation in Public Policy. In S. Z. Theodoulou \& M. A. Cahn (Eds.), Public Policy: The Essential Readings. New Jersey: Prentice Hall.

Palumbo, D. J. (1987). The Politics of Policy Evaluation. Beverly Hills: Sage.

Peter, J. M. (1992). Policy Learning and Failure. Journal of Public Policy, 12(4), 331-354. http://dx.doi.org/10.1017/S0143814X00005602

Ping, L. P. (2004). The Look East Policy, the Japanese Model, and Malaysia. In B. Welsh (Ed.), Reflections the Mahathir Years (pp. 318-324). Washington: The Paul H. Nitze School of Advanced International Studies (SAIS).

Rix, A. (1990). Japan's Foreign Aid Policy: A Capacity for Leadership? Pacific Affairs, 62(4), 461-475. http://dx.doi.org/10.2307/2759670

Rupa, D. (2012). Japanese SMEs keen to foray into global Halal mart via KL. News Strait Times. Retrieved June 25, 2013, from http://www.btimes.com.my/Current_News/BTIMES/articles/rup04c 
Sarawasthi, M. (2009). Pelaburan Jepun di Malaysia Meningkat Kepada AS\$1.87 billion. Retrieved November 12, 2012, from http://www.beranma.com/bernama/v3/bm/news_lite.php?id=460528

Taylor, S. J., \& Bogdan, R. (1998). Introduction to Qualitative Research Methods: A Guidebook and Resource. New York: John Wiley and Sons, Inc.

Teik, K. B. (1995). Paradoxes of Mahathirism. UK: Oxford University Press.

Wain, B. (2009). Malaysian Maverick: Mahathir Mohamad in Turbulent Times. London: Palgrave Macmillan. http://dx.doi.org/10.1057/9780230251236

Zielinksi, R. (1998). Role Model from Hell. Time, 29.

Zimmermann, D. H., \& Wieder, D. L. (1970). Ethnomethodology and Problem of Order: Comment on Denzin. In J. Douglas (Ed.), Understanding Everyday Life. Chicago: Aldine.

\section{Notes}

Note 1. Perspectives from Tun Mahathir Mohamad, a personal interviewed with him at KL Twin Tower on February 14th, 2013.

Note 2. Southeast Asia is prone to fundamentalist movements and accused of being the terrorist hub, See Kartini et al. 2012. Terrorist Threats: Measuring the terms and approaches. Asian Social Science, Vol. 8 No. 15 pp. 288-297

Note 3. 5S is referred to Seiri (sorting), Seiton (arranging), Seiso (cleaning-up), Seiketsu (unvarying), and Shisuke (practicing always) each is equivalently translated into the Malay language that has an equivalent meaning to word selected in English that places in each bracket.

Note 4. Other investments by Japan include technology projects such as Panasonic Energy Malaysia (US\$578 million), Ibiden investment (US\$906.3 million), quality hub projects in Selangor (US\$63 million) and expansion of Toyota Motor Corporation (US\$300 million), See Md Izwan (2012).

Note 5. See also Furuoka (2007) that views one of the reasons Japan was a bit resentful toward Mahathir's idea of establishing a strong regional economic bloc in Asia Pacific was due to the USA disapproval and non-supportive reaction.

\section{Copyrights}

Copyright for this article is retained by the author(s), with first publication rights granted to the journal.

This is an open-access article distributed under the terms and conditions of the Creative Commons Attribution license (http://creativecommons.org/licenses/by/3.0/). 